\title{
DRESS syndrome: a case report and literature review
}

\author{
Cláudia Sofia Cardoso, Ana Margarida Vieira, Ana Paula Oliveira \\ Department of Gastroenterology, Centro Hospitalar de Setúbal, Setúbal, Portugal \\ Correspondence to Dr Cláudia Sofia Cardoso, claudiamarcal@gmail.com
}

\section{Summary}

DRESS syndrome (drug rash, eosinophilia and systemic symptoms) is an idiosyncratic drug reaction characterised by rash, fever, lymphadenopathy and internal organ involvement. The authors report a case of this syndrome presenting with fever, generalised pruritus, macular rash and cholestatic hepatitis during allopurinol treatment. This case resolved with drug withdrawal, but the death rate in the setting of hepatic failure can reach $10 \%$. Rapid diagnosis is crucial as prompt withdrawal of the offending drug is the key of the treatment, while the potential role of corticosteroids remains controversial.

\section{BACKGROUND}

Drug rash with eosinophilia and systemic symptoms (DRESS) syndrome is a severe adverse drug reaction presenting with rash, fever, lymphadenopathy and single or multiple organ involvement. Cholestasis can occur although it is rare. Many drugs have been associated with this clinical entity, including allopurinol. The pathogenesis is not fully understood and may be multifactorial, involving immunological mechanisms and particular drug detoxification pathways.

\section{CASE PRESENTATION}

An 83-year-old woman presented to our department with fever, generalised pruritus and a history of macular rash affecting the face, abdomen and lower limbs with a 3 week duration. She had a history of arterial hypertension, cardiac arrhythmia and recently diagnosed hyperuricaemia and had been treated with atenolol and thiazide diuretics for several years and allopurinol for the past 6 weeks. On physical examination, during admission the temperature was $38.2^{\circ} \mathrm{C}$ and lesions due to pruritus were noted. There was no evidence of rash, mucous membrane involvement, lymphadenopathy or hepatosplenomegaly. Blood tests showed 2971 eosinophils/ $\mathrm{mm}^{3}$ (range 2-500), with no atypical lymphocytes, serum creatinine level of $1.2 \mathrm{mg} / \mathrm{dl}$ ( range 0.6-1.1), serum urea level of $61 \mathrm{mg} / \mathrm{dl}$ (range 10-45) and liver parameters alterations: aspartate and alanine aminotransferases values of 116 and 76 IU/1 $(\mathrm{N}<40), \gamma$-glutamyltransferase of $1251 \mathrm{IU} / \mathrm{l}(\mathrm{N}<30)$, alkaline phosphatase of $1062 \mathrm{IU} / 1(\mathrm{~N}<140)$ and total bilirubin of $2 \mathrm{mg} / \mathrm{dl}$ (range $0.4-1.4$ ), with a normal prothrombin time. Thyroid function tests, serum electrolytes, the autoimmunity study, urinalysis, faecal parasitological examination and abdominal ultra-sound, as well a bone marrow biopsy performed to exclude a myeloproliferative disorder, did not revealed any abnormalities. During the hospital stay there was a relapse of the macular rash affecting the face, trunk and lower limbs (figures 1 and 2) and at this time a DRESS syndrome secondary to allopurinol was suspected. It was decided to suspend the drug and corticoid therapy was started with topical hydrocortisone butyrate $0.1 \%$, twice a day during a week, and oral prednisolone $40 \mathrm{mg}$ per day for a month, with clinical and analytical improvement. At the end of the first month of steroid tapering, at a dose of $15 \mathrm{mg}$ per day, a macular rash relapse affecting the trunk and limbs was noted with the need of increasing the dose of oral prednisolone to the initial for 1 or 2 months followed by another attempt of tapering, with a drop of $10 \mathrm{mg}$ per week, and no register of recurrence until this time (12 months later and 4 months after stopping prednisolone). A normalisation of liver tests was documented through a period of 6 months and thyroid function tests 3 months post the acute presentation showed no abnormalities. The lymphocyte-stimulation test in vitro with allopurinol performed 9 months after the onset of the disease was found to be positive with a stimulation index $>2$, confirming this drug hypersensitivity.

\section{OUTCOME AND FOLLOW-UP}

No register of recurrence until this time (12 months later).

\section{DISCUSSION}

Drug-induced hypersensitivity syndrome was first described in 1936 during treatment with anticonvulsant drugs. ${ }^{1}$ Later on, the association with other drugs was established and the name 'DRESS syndrome' was suggested to describe this entity. The syndrome is characterised by rash, fever, lymphadenopathy and internal organ involvement (single or multiple). The pathogenesis is not fully understood. It has been suggested that certain drugs may cause a hypersensitivity reaction as a result of abnormalities in the production and detoxification of its active metabolites in patients with genetic or acquired variations in drug metabolism pathways. Its incidence ranges between 1 in 1000 and 1 in 10000 exposures. The aromatic anticonvulsants (phenytoin, phenobarbital, carbamazepine) and sulphonamides are the most common drugs described in this syndrome, but a variety of other drugs have been associated such as dapsone, allopurinol, captopril, calcium- channel blockers, ranitidine, thalidomide, minocicline, sulfasalazine, non-steroidal anti-inflammatory drugs, tuberculostatics, $\alpha$-metildope and antiretroviral drugs (zalcitabine, neviparine). ${ }^{2-4}$ The onset of the disease usually ranges from 2 to 6 weeks after the initiation of the 


\section{BMJ Case Reports}

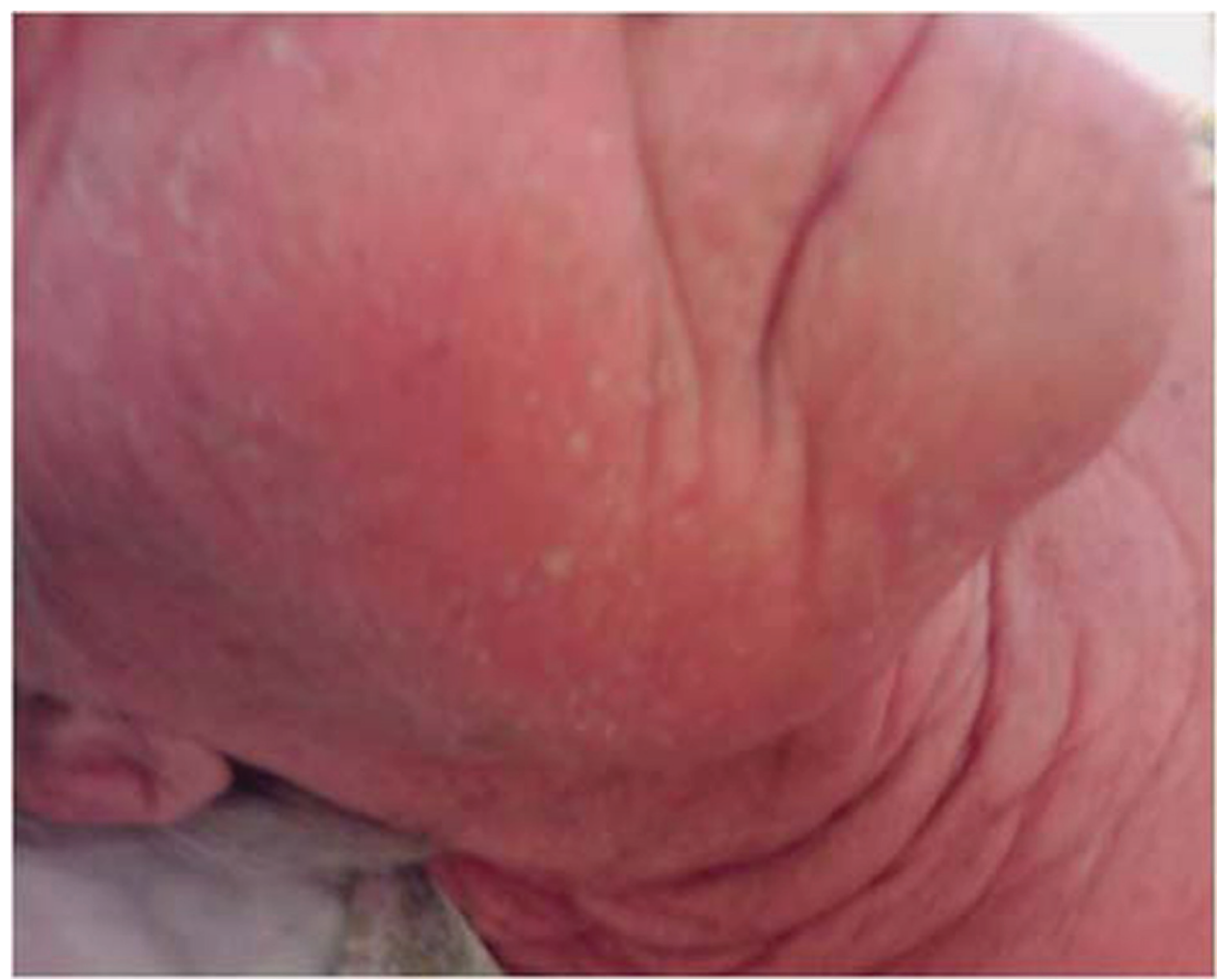

Figure 1 Macular rash affecting the face.

therapy. ${ }^{5}$ The first symptoms are usually fever and rash. The skin involvement is characterised by a morbilliform macular rash that appears first in the face, abdomen and upper limbs, becoming purpuric later on, especially in lower limbs. An exfoliative dermatitis appears when the lesions tend to vanish. ${ }^{6}$ In our patient, lesions due to pruritus were the main finding at presentation in the hospital, with no rash being noted. The patient is still ingesting allopurinol and there is no explanation for the absence of rash in the literature. We assume that the presence of exuberant lesions due to pruritus may lead to misdiagnosis of rash during the hospital admission. Facial oedema can also occur, as well conjunctivitis and pharyngeal mucosa erythema. The systemic involvement, that is thought to be the result of the eosinophilia, is not associated with the severity of skin lesions. Lymphadenopathy are present in $75 \%$ of the cases. The liver is the most common affected organ in DRESS syndrome. The findings may range from a transitory increase in liver enzymes to liver necrosis with fulminant hepatic failure, that is thought to be mediated by infiltration of eosinophils, resulting in death or liver transplantation. $^{2-4}$ These last two features are more frequently seen in women between the second and fourth decade of life with the outcome being independent of the use or dose of immunosuppressive therapy. A cholestatic injury pattern is seen in a minority of patients. The kidney, lung and heart are other sites that can be affected with interstitial nephropathy, pneumonitis, pericarditis and myocarditis being described in the literature. Arthritis, pancreatitis, encephalitis and thyroid involvement, with thyroiditis and hypothyroidism, have been reported to develop in a small subset of patients. 78
Diagnostic criteria for DRESS syndrome, published in 1996 by Bocquet et al, include the simultaneous presence of three conditions:

- Drug-induced skin eruption

- Eosinophilia $\geq 1500 / \mathrm{mm}^{3}$ and

At least one of the following systemic abnormalities:

- Lymphadenopathy

- Hepatitis (transaminases >2 ULN)

- Interstitial nephropathy

- Interstitial lung disease

- Myocardial involvement. ${ }^{9}$

There are a minimum of laboratory data that will help to differentiate DRESS syndrome from other severe drug reactions and to identify asymptomatic internal organ involvement. These data include complete blood cell count that usually shows eosinophilia and mononucleosislike atypical lymphocytosis, liver function parameters, serum creatinine levels and urinalysis. Thyroid stimulating hormone levels should also be measured and repeated after 2-3 months as hypothyroidism can emerge as a late complication. ${ }^{10}$

Allopurinol is one of the drugs that have been implied. The accumulation of one of allopurinol metabolites, oxypurinol, is the mechanism responsible for the syndrome appearance, especially in the setting of decreased renal clearance and the use of thiazide diuretics. ${ }^{11}$

The lymphocyte-stimulation test (LST) is a routinely available test that measures the proliferation of $\mathrm{T}$ cells to a drug in vitro. The test is considered positive if a certain stimulation index is achieved. Overall, a stimulation index more than 2 is needed to classify the test as positive. During the acute phase of drug hypersensitivity, the 


\section{BMJ Case Reports}

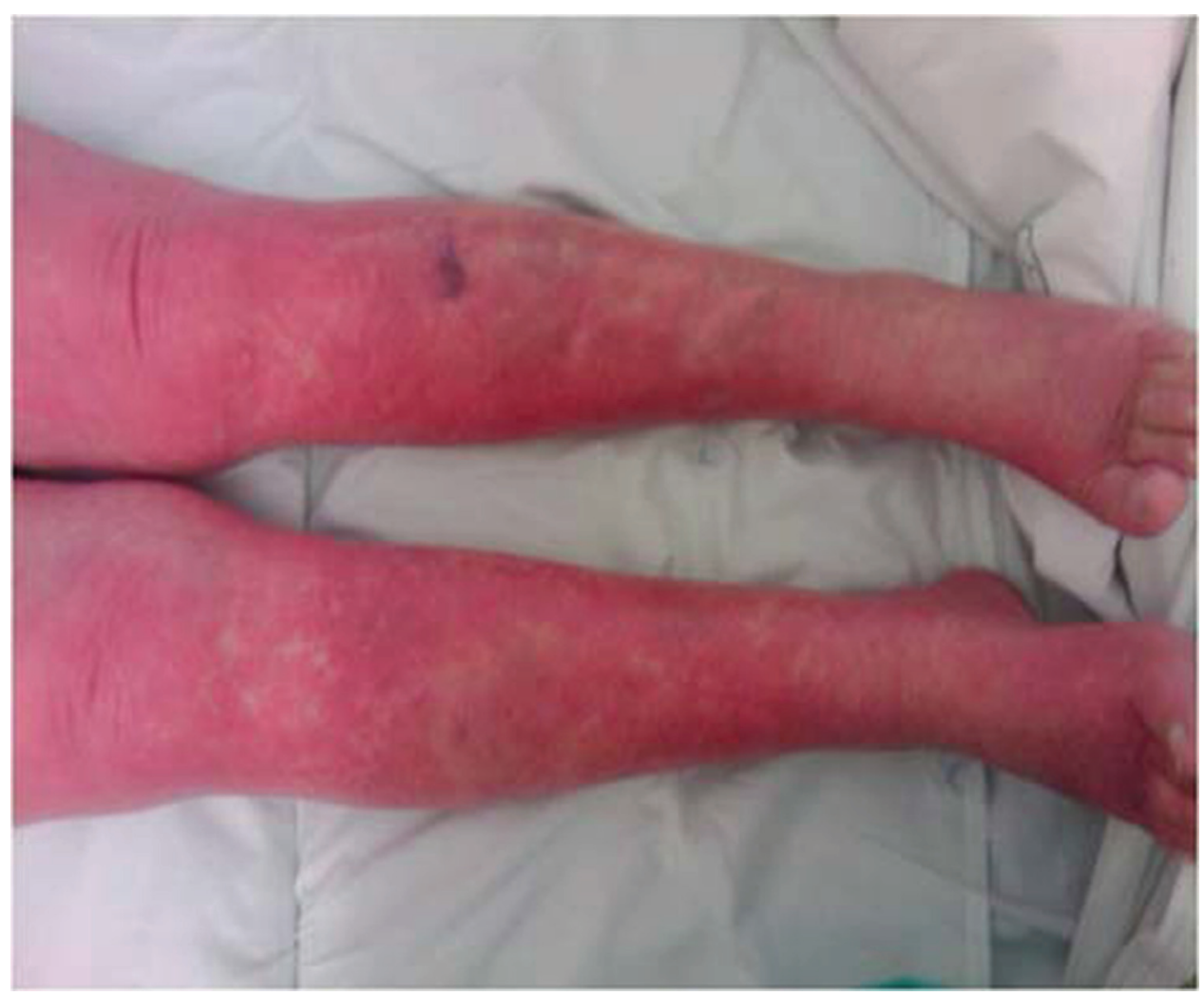

Figure 2 Lower limb purpuric lesions.

Table 1 DRESS syndrome: most common differential diagnoses

\begin{tabular}{|c|c|c|c|c|}
\hline & DRESS syndrome & SIS/TEN & HES & Kawasaki disease \\
\hline Cutaneomucous features & $\begin{array}{l}\text { Facial oedema, morbilliform } \\
\text { eruption, exfoliative dermatitis, } \\
\text { tense blisters }\end{array}$ & $\begin{array}{l}\text { Blisters, atypical targets, } \\
\text { cutaneomucous erosions }\end{array}$ & $\begin{array}{l}\text { Urticaria, angio- } \\
\text { oedema, morbilliform } \\
\text { eruption, infiltrated papules } \\
\text { or nodules }\end{array}$ & $\begin{array}{l}\text { Conjunctival congestion, } \\
\text { fissured lips, strawberrry } \\
\text { tongue, palmar erythema, } \\
\text { oedema of hands, periungueal } \\
\text { desquamation, polymorphous } \\
\text { exanthema }\end{array}$ \\
\hline \multicolumn{5}{|l|}{ Haematological abnormalities } \\
\hline Eosinophilia & + & - & + & - \\
\hline Presence of atypical lymphocytes & + & - & \pm & - \\
\hline \multicolumn{5}{|l|}{ Systemic involvement } \\
\hline Adenopathies & + & - & + & + \\
\hline Hepatitis & + & + & + & \pm \\
\hline Other organ involvement & $\begin{array}{l}\text { Interstitial nephritis, } \\
\text { pneumonitis, carditis }\end{array}$ & $\begin{array}{l}\text { Tubular nephritis, } \\
\text { tracheobronchial necrosis }\end{array}$ & $\begin{array}{l}\text { Carditis, pneumonitis, } \\
\text { encephalopaty, diarrhoea, } \\
\text { vomiting or abdominal pain }\end{array}$ & $\begin{array}{l}\text { Cardiovascular abnormalities, } \\
\text { diarrhoea, vomiting or abdominal } \\
\text { pain }\end{array}$ \\
\hline
\end{tabular}

SJS, Stevens-Johnson syndrome; TEN, toxic epidermal necrolysis; HES, hypereosinophilic syndrome.

immune system, in particular $T$ cells, is strongly activated and for this reason the test should be performed after clinical and analytical remission to avoid false positive results. The test has a sensitivity of $60-70 \%$. A positive LST is often a valuable contribution to the diagnosis (with only $2 \%$ of false positive results) but, due to its sensitivity, a negative test cannot exclude a drug hypersensitivity and therefore its performance is not mandatory in the presence of diagnostic criteria mentioned above. ${ }^{12}$

The skin biopsy may help to confirm the diagnosis but is usually not specific. It shows a lymphocytic infiltrate of the papillary dermis, which may contain eosinophils and is generally denser than in other drug reactions. ${ }^{13}$ The most common differential diagnoses include Stevens-Johnson syndrome (SJS), toxic epidermal necrolysis (TEN), hypereosinophilic syndrome and Kawasaki disease (table 1). ${ }^{14}$

So far, prompt withdrawal of the offending drug is the only undisputed way to treat drug hypersensitivity reactions. Supportive therapy includes antipyretics and the use of topical steroids to improve symptoms. ${ }^{15} 16$ Systemic corticosteroids can reduce symptoms of delayed hypersensitivity reactions.

They are known to inhibit the effect of interleukin-5 on eosinophils accumulation occurring in this syndrome, which may explain their benefit in the treatment. Dramatic improvement in clinical symptoms and laboratory findings has been observed soon after the beginning of corticoid therapy in independent case reports. Several authors 


\section{BMJ Case Reports}

suggest their use when internal organ involvement exists, although the ideal dosage and the length of therapy are unknown. However, randomised controlled trials are lacking, and whether steroids should be administered remains controversial. ${ }^{17} 18$ Relapses have also been described after tapering or withdrawal of systemic steroids. Death rate in DRESS syndrome is about $10 \%$, mostly due to liver failure. $^{2-4}$

\section{Learning points}

- DRESS syndrome is an idiosyncratic drug reaction characterised by rash, fever, lymphadenopathy and internal organ involvement

- Allopurinol is one of the drugs that have been implied, especially in the setting of decreased renal clearance and the use of thiazide diuretics.

- Prompt withdrawal of the offending drug is the only undisputed way to treat drug hypersensitivity reactions.

- Systemic corticosteroids can reduce symptoms of delayed hypersensitivity reactions. However, randomised controlled trials are lacking, and whether steroids should be administered remains controversial.

\section{Competing interests None.}

Patient consent Obtained.

\section{REFERENCES}

1. Saltzstein SL, Ackerman LV. Lymphadenopathy induced by anticonvulsant drugs and mimicking clinically pathologically malignant lymphomas. Cancer 1959:12:164-82.
2. Tas $\mathbf{S}$, Simonart T. Drug rash with eosinophilia and systemic symptoms (DRESS syndrome). Acta Clin Belg 1999;54:197-200.

3. Roujeau JC. Treatment of severe drug eruptions. J Dermatol 1999;26:718-22.

4. Callot V, Roujeau JC, Bagot M, et al. Drug-induced pseudolymphoma and hypersensitivity syndrome. Two different clinical entities. Arch Dermatol 1996;132:1315-21.

5. Roujeau JC. Clinical heterogeneity of drug hypersensitivity. Toxicology 2005;209:123-9.

6. Bocquet $\mathbf{H}$, Roujeau JC. Les reactions cutanées sévères induites par les médicaments. Ver Fr Allergol 1997;37:651-9.

7. Begon E, Roujeau JC. [Drug hypersensitivity syndrome: DRESS (Drug Reaction with Eosinophilia and Systemic Symptoms)]. Ann Dermatol Venereol 2004;131:293-7.

8. Michel F, Navellou JC, Ferraud D, et al. DRESS syndrome in a patient on sulfazalazine for rheumatoid arthritis. Revue du rheumatism 2005;72:92-6.

9. Ben $\mathbf{m}$ `rad M, Leclerc-Mercier S, Blanche P, et al. Drug-induced hypersensitivity syndrome: clinical and biological disease patterns in 24 patients. Medicine(Baltimore) 2009;88:131-40.

10. Gupta A, Eggo MC, Uetrecht JP, et al. Drug-induced hypothyroidism: the thyroid as a target organ in hypersensitivity reactions to anticonvulsants and sulfonamides. Clin Pharmacol Ther 1992;51:56-67.

11. Shalom R, Rimbroth $S$, Rozenman D, et al. Allopurinol-induced recurrent DRESS syndrome: pathophysiology and treatment. Ren Fail 2008;30:327-9.

12. Pichler WJ, Tilch J. The lymphocyte transformation test in the diagnosis of drug hypersensitivity. Allergy 2004;59:809-20.

13. De Vriese AS, Philippe J, Van Renterghem DM, et al. Carbamazepine hypersensitivity syndrome: report of 4 cases and review of the literature. Medicine (Baltimore) 1995;74:144-51.

14. Yamaguchi M, Ohta A, Tsunematsu T, et al. Preliminary criteria for classification of adult Still's disease. J Rheumatol 1992;19:424-30.

15. Sullivan JR, Shear NH. The drug hypersensitivity syndrome: what is the pathogenesis? Arch Dermatol 2001;137:357-64.

16. Knowles S, Shapiro L, Shear NH. Serious dermatologic reactions in children. Curr Opin Pediatr 1997:9:388-95.

17. Hellman C, Lönnkvist K, Hedlin G, et al. Down-regulated IL-5 receptor expression on peripheral blood eosinophils from budesonide-treated children with asthma. Allergy 2002;57:323-8.

18. Chopra S, Levell NJ, Cowley G, et al. Systemic corticosteroids in the phenytoin hypersensitivity syndrome. Br J Dermatol 1996;134:1109-12.

This pdf has been created automatically from the final edited text and images.

Copyright 2011 BMJ Publishing Group. All rights reserved. For permission to reuse any of this content visit http://group.bmi.com/group/rights-licensing/permissions.

BMJ Case Report Fellows may re-use this article for personal use and teaching without any further permission.

Please cite this article as follows (you will need to access the article online to obtain the date of publication).

Cardoso CS, Vieira AM, Oliveira AP. DRESS syndrome: a case report and literature review. BMJ Case Reports 2011;10.1136/bcr.02.2011.3898, date of publication

Become a Fellow of BMJ Case Reports today and you can:

- Submit as many cases as you like

- Enjoy fast sympathetic peer review and rapid publication of accepted articles

- Access all the published articles

- Re-use any of the published material for personal use and teaching without further permission

For information on Institutional Fellowships contact consortiasales@bmjgroup.com

Visit casereports.bmj.com for more articles like this and to become a Fellow 